\title{
Clinical learning environment of nursing and midwifery students in Ghana
}

Florence Assibi Ziba ${ }^{1 *}$, Vida Nyagre Yakong ${ }^{2}$ and Zakari Ali ${ }^{3,4}$

\begin{abstract}
Background: Data on student experience of the clinical learning environment in Ghana are scarce. We therefore aimed to assess students' evaluation of the clinical learning environment and the factors that influence their learning experience.

Methods: This was a cross-sectional survey of 225 undergraduate nursing and midwifery students. We used the Clinical Learning Environment and Supervision + Nurse Teacher (CLES +T) evaluation scale to assess students' experience of their clinical placement. The association between student demographic characteristics and clinical placement experience was determined using t-test or ANOVA.

Results: Most of the sampled students were Nurses (67\%) and in the third year of training (81\%). More students received supervision from a nurse (57\%) during clinical placement and team supervision (67\%) was the most common during clinical placement. Nursing students were more likely to rate their clinical experience better than midwifery students $(p=0.002$ ). Students who had increased contact with private supervisors were also more likely to rate their experience higher $(p=0.002)$. Clinical experience was also rated higher by students who received successful supervision compared to those who had unsuccessful or team supervision ( $p=0.001)$.

Conclusion: Team supervision is high in health facilities where students undertake clinical placement in Ghana. Frequent contact with private supervisor and successful supervision are associated with better rating of clinical experience among Ghanaian undergraduate nursing and midwifery students.
\end{abstract}

Keywords: CLES+T, Clinical placement, Learning environment, Nursing and midwifery, Ghana

\section{Background}

Nursing care is pivotal in the health care services worldwide. Globally, nurses and midwives constitute $59 \%$ of the health workforce [1]. In Ghana, out of the 115, 650 health workers employed by the government, nurses and midwives account for 58\% [2]. The axillary nurses (community and enrolled nurses; trained for 2 years) make up the majority (53\%) of the total nursing and midwifery workforce whiles professional nurses (with at least 3 years of training resulting in the acquisition of diploma, undergraduate, postgraduate qualifications, or

\footnotetext{
* Correspondence: aziba@uds.edu.gh

${ }^{1}$ Department of Nursing, University for Development Studies, Tamale, Ghana Full list of author information is available at the end of the article
}

specific speciality areas of study) account for $47 \%[2,3]$. The nurse serves as the main vessel that convey most interventions and care necessary for individuals utilizing health care services. For nurses to efficiently perform the myriads of duties, it depends on their ability to apply theory to practice $[4,5]$. Hence, nursing training involves both theory and practical training. Each aspect of the training carries important weight.

The clinical skills acquisition of nurses is so important that the Nursing and Midwifery Council (NMC) of Ghana, a body mandated to regulate the training of nurses increased the clinical contact hours of students to $432 \mathrm{~h}, 624 \mathrm{~h}$ and $576 \mathrm{~h}$ for the first, second and third year of training respectively [6]. According to Benner [7], skills acquisition is not an event but a process where

(c) The Author(s). 2021 Open Access This article is licensed under a Creative Commons Attribution 4.0 International License, which permits use, sharing, adaptation, distribution and reproduction in any medium or format, as long as you give appropriate credit to the original author(s) and the source, provide a link to the Creative Commons licence, and indicate if changes were made. The images or other third party material in this article are included in the article's Creative Commons licence, unless indicated otherwise in a credit line to the material. If material is not included in the article's Creative Commons licence and your intended use is not permitted by statutory regulation or exceeds the permitted use, you will need to obtain permission directly from the copyright holder. To view a copy of this licence, visit http://creativecommons.org/licenses/by/4.0/ The Creative Commons Public Domain Dedication waiver (http://creativecommons.org/publicdomain/zero/1.0/) applies to the data made available in this article, unless otherwise stated in a credit line to the data. 
individual nurses start as novice and gradually become experts. Whiles the acquisition of knowledge on the theory is done in the classroom, the skills acquisition is done in the skills laboratory and clinical learning environment or setting depending on one's level of study.

The clinical learning environment (CLE) is a complex and constantly changing setting [8]. The CLE can be influenced by several factors such as the kind of supervisor, the quality of feedback received by students, the context and the students $[9,10]$. Much of skills teaching are done by the nurses in clinical practice regardless of their level of education and expertise.

This implies that the quality of clinical teaching of students depends on the efficiency of the supervisor they meet in the clinical facility [11, 12]. In Ghana, it is regarded the responsibility of every registered nurse or midwife to provide teaching or guidance for students who work with them on their shift without any specific training for that purpose. The registered nurses supervise students and do not receive payments by any of the institutions for this service. Some of these supervisors may not be adequately prepared or motivated for the task of clinical teaching [9]. According to Chan and Ip [13], their relationship is very key and determines the kind of learning environment created. A positive learning clinical environment is a result of good relationship between the supervisor and the students. Nursing students will always be motivated to learn in environments where there is mutual respect and students are involved in the team and supported with their decision making [4].

Constructs of the clinical learning environment positively influence students' satisfaction with their learning activities [14]. The pedagogical atmosphere, ward manager leadership style and supervisory relationship are important factors that contribute to satisfaction with the clinical environment. Students who have the chance to meet a supervisor on more regular basis tend to well appreciate the contribution of the clinical environment to their skills learning. Having access to a supervisor or mentor allows the student to learn more and improve the skills learning.

Despite the importance of clinical learning for nursing students, it comes with some challenges to students, faculty and supervisors. For students, depending on the level of study it can be demanding especially when students feel, they lack the right skills for a particular assigned task [15]. They worry about the probability of supervisors holding negative perceptions about them which could affect their grading and therefore may come under "pressure" to please their supervisors [9].

Crowding of students in the clinical setting is a major challenge to clinical teaching and learning $[16,17]$. Overcrowding in the ward makes it difficult for both students and clinical supervisors to engage meaningfully.
When student numbers are high it means studentpreceptor ratios will be higher than required for effective clinical learning. When students are more than the physical space can accommodate it becomes very difficult for staff to even assist them to learn clinical skills [18]. In Ghana, the ration of a supervisor to student is approximately 1: 10 or more students in a shift [19]. This is because students are required to do their clinical placement only in the hospital setting. Therefore, the need to improve clinical nursing education is an important aspect of training of nurses. Thematic areas of importance in improving clinical nursing education include having positive clinical environment, effective clinical supervision, adequate assessment of students and clinical-academic collaborations [20]. However, there are no current studies reporting the student evaluation of their clinical placement experience in Ghana. We examined nursing and midwifery students' evaluation of their clinical placement using the CLES+T.

\section{Methods \\ Study design and setting}

This was a cross-sectional study involving undergraduate nursing and midwifery students of the University for Development Studies on clinical placement in health facilities in the Tamale Metropolis.

The Tamale Metropolitan Assembly (normally of a population of $\geq 250,000$ ) is one of the 260 Metropolitan, Municipal (normally of a $\geq 95,000$ population) and District (normally of a $\geq 75,000$ population) Assemblies in Ghana. Tamale is the capital town of the metropolis and the Northern region of Ghana. Until 2004, it was a municipality. It is the largest of the 16 metropolitan, municipal and district assemblies in the northern region of Ghana. According to the 2010 population and housing census, the metropolis has a population 223,252 made up of 49.8 and $50.2 \%$ males and females respectively. Though the main language of the people is Dagbani, due to its cosmopolitan nature, all the different Ghanaian languages can be heard in the municipality [21].

Apart from the University for Development studies which trains nurses and midwives among other health professionals, the metropolis has two of the oldest nursing training institutions in Ghana; the Tamale Nursing and midwifery training college and the Tamale community health nursing school. One of the three teaching hospitals in Ghana- The Tamale Teaching Hospital, is located in this metropolis. Students are, therefore, placed in this hospital and three other public hospitals (Tamale Central, West and the Seventh Day Adventist hospitals) for the clinical practicum.

\section{Sampling and clinical placement}

Purposive and convenient sampling techniques were used. Purposive, because only students who were toward 
the end of their studies (third and fourth years' students) for nursing and midwifery degree were selected to participate in the study. Undergraduate education in Ghana is for 4 years and range from level 100 to level 400. The clinical supervisors sign off the clinical assessment of the students. This assessment constitutes $40 \%$ of the mark a student will score in his or her practical exams for the semester. The rest of the $60 \%$ is from Objective Structured Clinical Examination (OSCE) conducted by the training institutions (the school). The clinical placement of undergraduate students is divided into intra semester (students are placed for 1 day each week whiles they continue with their lectures and academic activities) and after semester (when students are done with their lectures and examination for the semester and proceed to spend the rest of it clinical placement. This comprise of four to ten weeks block for first and second semesters respectively). This was to ensure that students had enough exposure to clinical placement to enable them to evaluate their experience. However, it was convenient because students in these year levels who were available and willing to participate were selected.

The questionnaire was administered to students by the researchers in the university campus. The questionnaire was self-administered and participants were allowed to take the questionnaires home and return completed copies to the researchers.

\section{The study questionnaire}

We used the English version of the Clinical Learning Environment and Supervision + Nurse Teacher $($ CLES +T) evaluation scale [22] with prior permission. This psychometric testing scale consists of a total of 34 items within five sub-dimensions. The sub-dimensions are: pedagogical atmosphere on the ward (nine items), leadership style of the ward manager (four items), premises of nursing on the ward (four items), supervisory relationship (eight items), and role of the nurse teacher in clinical practice (nine items). The questions were scored on a five-point Likert scale of 1 to 5 . The scores were as follows: $1=$ fully disagree, $2=$ disagree to some extent, $3=$ neither agree nor disagree, $4=$ agree to some extent and $5=$ fully agree. We added questions on programme of study and level.

\section{Statistical analysis}

Statistical analyses were done using SPSS version 21. Demographic characteristics of students are presented as frequencies and percentages. Internal consistency was checked for the overall scale and each of the five dimensions using Cronbach's alpha. There was high internal consistency of the overall CLES $+\mathrm{T}$ (Cronbach's alpha = 0.904). The five dimensions also showed high internal consistency with Cronbach's alpha values ranging from
0.713 to 0.903 which showed the suitability of the use of this scale (Additional file 1). The method of supervision was categorised into three based on responses to six questions. Unsuccessful supervision was assigned based on a combination of three alternative questions: (i) the student did not have a named supervisor; (ii) a personal supervisor was named, but the relationship with this person did not work; and (iii) the named supervisor changed during the training course. Team supervision was assigned based on a combination of: (i) the supervisor varied according to shift or place and (ii) the supervisor had several students. Successful supervision was where students had a named mentor and the relationship worked in practice $[23,24]$.

An overall mean score of the questionnaire was calculated for each student by calculating the mean score of all questions. Scores on the five sub-dimensions were also calculated for each student using scores of the questions that make up those dimensions. Higher scores indicate more agreement with the statements.

The association between student demographic characteristics and clinical placement experience and mean scores was determined using t-test or ANOVA as appropriate. We determined associations of the overall mean score on CLES+T and the sub-dimensions using the mean scores (continuous) as dependent variable and demographic characteristics (binary/categorical) and clinical experience (binary/categorical) as independent variables.

\section{Results}

\section{Background characteristics and clinical experience of} students

Majority of the sampled students were undergraduate nursing students (67\%) and were in their third year (81\%) of study. More than five in ten students received supervision from a nurse (57\%) during clinical placement while nurse specialists (4\%) provided least supervision. Team supervision (where students are not assigned to specific supervisor but are qualified or registered nurses on duty for the shift do the supervision) (67\%) was the most common supervision students received during clinical placement. About three in ten students reported unsuccessful supervision (29\%) while only $4 \%$ received successful supervision during clinical placement. Moreover, most students did not have one on one contact with their supervisor (46\%) and the most frequent private contact with clinical supervisor was once or twice during the course of placement (27\%) (Table 1).

\section{Mean scores on the overall scale and sub-dimensions}

Students had good perceptions of their clinical placement (mean CLES $+\mathrm{T}=3.24$ ). Student perceptions on the sub-divisions of CLES $+\mathrm{T}$ varied considerably. The 
Table 1 Background characteristics and clinical experience

\begin{tabular}{ll}
\hline Characteristic, $\mathbf{n}$ (\%) & Summary values $(\boldsymbol{n}=\mathbf{2 2 5})$ \\
\hline Programme of study & $150(66.7)$ \\
BSc. Nursing & $75(33.3)$ \\
BSc. Midwifery & \\
Level (year) & $42(18.7)$ \\
300 (third) & $183(81.3)$ \\
400 (fourth) & $129(57.3)$ \\
Title of clinical supervisor & $8(3.6)$ \\
Nurse & $16(7.1)$ \\
Nurse specialist & $40(17.8)$ \\
Assistant ward manager & $32(14.2)$ \\
Sister/ward manager & \\
Midwife & $66(29.3)$ \\
Method of supervision & $151(67.1)$ \\
Unsuccessful supervision & $8(3.6)$ \\
Team supervision & $27(12.0)$ \\
Successful supervision & $104(46.2)$ \\
Frequency of private contact with supervisor \\
Not at all & $61(27.1)$ \\
Once or twice during the course & \\
Less than once a week & \\
About once a week & \\
More often & \\
\hline
\end{tabular}

highest score was for the Leadership style of the ward manager (3.6) while Role of the nurse teacher in clinical practice (3.06) dimension of CLES $+\mathrm{T}$ was least scored (Table 2).

\section{Association between student demographics, clinical experience and mean CLES + T score}

The results show that mean CLES + T score was not associated with year of study even though third year students had a little higher scores than fourth year students (3.3 vs 3.2, $p=0.405)$. Mean CLES + T score associated weakly with the title of assigned clinical supervisor $(p=$ 0.063). There was evidence of association between mean

Table 2 Mean score on the CLES $+\mathrm{T}$ and dimensions

\begin{tabular}{ll}
\hline Item & Mean (SD) \\
\hline Total CLES + T & $3.24(0.60)$ \\
Dimensions of CLES + T & \\
$\quad$ Pedagogical atmosphere & $3.29(0.72)$ \\
Leadership style of the ward manager & $3.63(0.85)$ \\
Premise of nursing on the ward & $3.19(0.94)$ \\
Supervisory relationship & $3.20(0.96)$ \\
Role of the nurse teacher in clinical practice & $3.07(0.84)$ \\
\hline
\end{tabular}

score and student programme of study, with nursing students scoring a little higher than midwifery students ( $p=$ 0.002); hence, nursing students perceived their clinical learning environments better than midwifery students. Students who had successful supervision were more likely to have higher scores than those who did not ( $p=$ 0.001). Students who reported increased contact with their private supervisors had higher mean scores ( $p=$ 0.002) (Table 3).

\section{Association between student demographics, clinical experience and mean score of the dimensions of CLES + $T$}

We investigated the relationship between mean scores of the five dimensions of CLES $+\mathrm{T}$ and student's demographic factors and clinical placement experience. The data show that method of supervision and frequency of private contact with supervisor were associated with the Pedagogical atmosphere dimension of CLES + T. For example, while students who received successful supervision (3.6) had better perceptions of the Pedagogical atmosphere, those who had unsuccessful supervision (3.1) and those who received team supervision (3.4) had poor perceptions. Only the method of supervision

Table 3 Association between student demographics, clinical experience and mean CLES + T score

\begin{tabular}{|c|c|c|}
\hline Factor & Mean (SD) & Test statistic \\
\hline \multicolumn{3}{|l|}{ Programme of study } \\
\hline BSc. Nursing & $3.15(0.55)$ & $t=-3.1, p=0.002$ \\
\hline BSc. Midwifery & $3.14(0.67)$ & \\
\hline \multicolumn{3}{|l|}{ Level (year) } \\
\hline 300 (third) & $3.32(0.75)$ & $\mathrm{t}=0.84, p=0.405$ \\
\hline 400 (fourth) & $3.22(0.56)$ & \\
\hline \multicolumn{3}{|l|}{ Title of clinical supervisor } \\
\hline Nurse & $3.15(0.55)$ & $F=2.27, p=0.063$ \\
\hline Nurse specialist & $3.36(0.51)$ & \\
\hline Assistant ward manager & $3.44(0.53)$ & \\
\hline Sister/ward manager & $3.42(0.63)$ & \\
\hline Midwife & $3.26(0.75)$ & \\
\hline \multicolumn{3}{|l|}{ Method of supervision } \\
\hline Unsuccessful supervision & $3.07(0.68)$ & $F=7.38, p=0.001$ \\
\hline Team supervision & $3.38(0.54)$ & \\
\hline Successful supervision & $3.83(0.43)$ & \\
\hline \multicolumn{3}{|c|}{ Frequency of private contact with supervisor } \\
\hline Not at all & $3.14(0.61)$ & $F=4.51, p=0.002$ \\
\hline Once or twice during the course & $3.26(0.55)$ & \\
\hline Less than once a week & $2.83(0.53)$ & \\
\hline About once a week & $3.46(0.60)$ & \\
\hline More often & $3.53(0.53)$ & \\
\hline
\end{tabular}


students received was associated with the Leadership style of the ward manager dimension of CLES $+\mathrm{T}$ ( $p=$ 0.023). Premise of nursing on the ward dimension was associated with the programme of study of students and their frequency of private contact with supervisor (Table 4).

In addition, Supervisory relationship was associated with programme of study ( $p=0.002)$, frequency of contact with private supervisor $(p=0.001)$ and method of supervision received $(p<0.001)$. The last dimension of CLES + T: Role of nurse teacher in clinical practice was also associated with programme of study $(p=0.010)$ and method of supervision $(p=0.015)$ (Table 5$)$.

\section{Discussion}

In this cross-sectional study among undergraduate nursing and midwifery students in the Tamale metropolis of Ghana, we assessed students' evaluation of their clinical

Table 4 Association between student demographics, clinical experience and mean score of first three dimensions of CLES + $\mathrm{T}$

\begin{tabular}{|c|c|c|}
\hline Dimension & Mean (SD) & Test statistic \\
\hline \multicolumn{3}{|l|}{ Pedagogical atmosphere } \\
\hline \multicolumn{3}{|l|}{ Method of supervision } \\
\hline Unsuccessful supervision & $3.06(0.81)$ & $F=5.07, p=0.007$ \\
\hline Team supervision & $3.37(0.66)$ & \\
\hline Successful supervision & $3.56(0.76)$ & \\
\hline
\end{tabular}

Frequency of private contact with supervisor

$\begin{array}{ll}\text { Not at all } & 3.17(0.76) \quad F=5.45, p<0.001 \\ \text { Once or twice during the course } & 3.32(0.65) \\ \text { Less than once a week } & 2.70(0.60) \\ \text { About once a week } & 3.64(0.55) \\ \text { More often } & 3.60(0.63)\end{array}$

Leadership style of the ward manager

Method of supervision

Unsuccessful supervision

$3.39(0.84) \quad F=3.86, p=0.023$

Team supervision

$3.72(0.84)$

Successful supervision

$3.75(0.91)$

Premise of nursing on the ward

Programme of study

BSc. Nursing $\quad 3.09(0.93) \quad \mathrm{t}=-2.23, p=0.027$

BSc. Midwifery

$3.39(0.96)$

Frequency of private contact with supervisor

$\begin{array}{ll}\text { Not at all } & 3.10(0.93) \quad F=3.13, p=0.016 \\ \text { Once or twice during the course } & 3.14(0.98) \\ \text { Less than once a week } & 2.73(0.84) \\ \text { About once a week } & 3.35(0.97) \\ \text { More often } & 3.70(0.81)\end{array}$

Table 5 Association between student demographics, clinical experience and mean score of last two dimensions of CLES + T

\begin{tabular}{|c|c|c|}
\hline Dimension & Mean (SD) & Test statistic \\
\hline \multicolumn{3}{|c|}{ Supervisory relationship } \\
\hline \multicolumn{3}{|c|}{ Programme of study } \\
\hline BSc. Nursing & $3.06(0.93)$ & $\mathrm{t}=-3.09, p=0.002$ \\
\hline BSc. Midwifery & $3.48(0.96)$ & \\
\hline
\end{tabular}

Frequency of private contact with supervisor

$\begin{array}{lll}\text { Not at all } & 2.98(0.93) \quad F=4.95, p=0.001 \\ \text { Once or twice during the course } & 3.97(0.88) \\ \text { Less than once a week } & 3.55(0.89) \\ \text { About once a week } & 3.49(0.94) \\ \text { More often } & 3.36(0.94) \\ \text { Method of supervision } & \\ \text { Unsuccessful supervision } & 2.93(1.10) \quad F=8.42, p<0.001 \\ \text { Team supervision } & 3.26(0.86) \\ \text { Successful supervision } & 4.27(0.31)\end{array}$

Role of the nurse teacher in clinical practice

Programme of study

BSc. Nursing

$2.97(0.81) \quad \mathrm{t}=-2.60, p=0.010$

BSc. Midwifery

$3.27(0.86)$

Method of supervision

Unsuccessful supervision

$3.07(0.82) \quad F=4.30, p=0.015$

Team supervision

$3.02(0.83)$

Successful supervision

$3.90(0.76)$

experience in health facilities using the Clinical Learning Environment and Supervision + Nurse Teacher (CLES $+\mathrm{T})$ evaluation scale. The main findings are that; more students received supervision from nurses during clinical placement and team supervision was the most common supervisory type. Nursing students were more likely to rate their clinical experience better than midwifery students and students who had increased contacts with private supervisors were more likely to rate their experience higher. Clinical experience was also evaluated better by students who received successful supervision compared to those who had other forms of supervision.

The higher likelihood of nurses than other health professionals such as midwives to provide supervision to students on clinical placement in this setting may be explained by the type of skills and competencies students are placed to acquire. This is because many basic skills for both nursing and midwifery as well as advanced skills are taught by nurses as most of those skills are general until students, such as the midwifery students move on to perform specific midwifery skills. The higher rating of clinical placement by nursing students than midwifery students in the present study could mean that midwifery students were expecting that since they are midwives 
they needed to have been supervised by only midwives; there is also the tendency to view midwifery practice totally separate from nursing practice, which in fact, should not be the case because most basic skills performed in midwifery practice also occur in nursing practice. This is a perception that needs more exploration to inform students' experience and appreciation of their practice and skills acquisition. It is, therefore, useful for students to be made aware of this ahead of their clinical placement to avoid being unsatisfied with the initial nurse dominant supervision they receive.

We find that frequency of contact with private supervisor was associated with high evaluation of clinical experience by both nursing and midwifery students. These findings are consistent with the results from Cyprus [14], Slovakia [25], northern Italy [26] and Sweden [27] where nursing students evaluated their clinical experience better with private supervision. As team supervision was higher and likely to be poor among students, it is reasonable that contact with private supervisors with a high tendency for tailored training to receive high rating. There is high need for private supervision as revealed in the study and calls for students to make more efforts and make good use of this opportunity whenever available to gain the needed skills. We recommend that clinic or ward staff also endeavour to provide private supervision to increase the quality of clinical experience of students.

Consistent with previous findings [14, 23, 26], successful supervision was associated with higher evaluation of student clinical experience. However, this has not always been the case in all studies [28]. Successful supervision constitutes having a named mentor and a perception of the relationship having worked out. Therefore, it is understandable that students who had successful supervision rated their overall clinical experience better. For improved clinical experience of students, mentors and students should work together to achieve a successful supervision.

To the best of our knowledge, this is the first attempt to report nursing and midwifery students' evaluation of their clinical placement in Ghana. The findings could be useful to health institutions and providers such as hospitals and clinics involved in the training of nursing and midwifery students to achieve better clinical experience and skills acquisition. However, the results of the study should be interpreted keeping some limitations in mind. First, our sample consisted of more nursing students than midwifery students, so the generalizability of the findings may be less applicable to midwifery students. Second, most supervisors at the ward level were often of a lower educational level than the students which could affect the quality of supervision and supervisory relationship. While this is not a typical limitation of the study, it may have influenced the evaluation of student experience of their clinical placement. Third, the CLES+T questionnaire has not been validated in this setting. However, we do not think this would have affected our results greatly, as the questionnaires were administered in the original English language not translated into a different Ghanaian language. The tests for reliability of the CLES+T using Cronbach's alpha were also within acceptable ranges indicating its suitability. In spite of these limitations, our results provide important insights into the experiences of nursing and midwifery students during clinical placement in Ghana.

\section{Conclusion}

Team supervision is high in health facilities where students undertake clinical placement in Ghana; nursing students are more likely to rate their clinical experience better than midwifery students and students with increased contacts with private supervisors were more likely to rate their experience better. Frequent contact with private supervisor and successful supervision are associated with better rating of clinical experience among Ghanaian undergraduate nursing and midwifery students.

\section{Supplementary Information}

The online version contains supplementary material available at https://doi. org/10.1186/s12912-020-00533-8.

Additional file 1. Test for internal consistency of CLES $+\mathrm{T}$ (Cronbach's alpha).

Abbreviation

CLES+T: Clinical Learning Environment and Supervision + Nurse Teacher evaluation scale

Acknowledgements

We are grateful to all the participants of the study. We also thank the original authors of CLES+T for giving the permission to use the questionnaire for this study.

\section{Authors' contributions}

FAZ conducted the interview and wrote the manuscript. VNY Planned and designed the study. ZA entered, performed data analysis, results interpretation and wrote manuscript. All authors reviewed the final manuscript draft and approved the final version for publication.

\section{Funding}

We did not receive external funding for this study.

\section{Availability of data and materials}

The data supporting the conclusions of this article are included within the manuscript. The datasets could be obtained from the corresponding author upon reasonable request.

\section{Ethics approval and consent to participate}

The study was granted ethical approval by the Research and Ethical Committee of the School of Allied Health Sciences of the University for Development Studies, Tamale, Ghana. Participation was purely voluntary. Participants verbally agreed to participation and provided written informed consent for participation. Participants were told they could decide to withdraw from the study anytime without any consequences. The purpose of the study and the assurance of confidentiality of information were 
explained to participants. They were also told they could decide not to answer any question they felt uncomfortable with.

\section{Consent for publication}

Not applicable.

\section{Competing interests}

The authors declare that they have no competing interests.

\section{Author details}

'Department of Nursing, University for Development Studies, Tamale, Ghana. ${ }^{2}$ Department of Midwifery, University for Development Studies, Tamale, Ghana. ${ }^{3}$ Nutrition Theme, MRC Unit The Gambia at the London School of Hygiene and Tropical Medicine, Atlantic Boulevard, Fajara, P. O. Box 273, Banjul, The Gambia. ${ }^{4}$ Department of Nutritional Sciences, School of Allied Health Sciences, University for Development Studies, P.O Box 1883, Tamale, Ghana.

Received: 3 January 2020 Accepted: 26 December 2020

Published online: 07 January 2021

\section{References}

1. WHO: State of the world's Nursing 2020 Investing in education, jobs and leadership. 2020

2. Asamani JA, Amertil NP, Ismaila $H$, Francis AA, Chebere MM, NabyongaOrem J. Nurses and midwives demographic shift in Ghana-the policy implications of a looming crisis. Hum Resour Health. 2019;17(1):32.

3. Ghana Health Service: The health sector in Ghana Facts and figures 2018. 2018.

4. Ali WG, Banan SHAE, Al Seraty WH. Effective clinical learning environment as perceived by nursing students at Al Dawadmi, applied medical sciences college: actual versus preferred characteristics. Int J Nurs Didactics. 2015; 5(05):01-6.

5. Eta $V E$, Atanga MB, Atashili J, D'Cruz G. Nurses and challenges faced as clinical educators: A survey of a group of nurses in Cameroon. Pan Afr Med J. 2011:8(1).

6. Nursing and Midwifery Council of Ghana. Curriculum for the Registered General Nursing (RGN) Programme. Accra Ghana: NMC; 2015.

7. Benner P. From novice to expert. Am J Nurs. 1982;82(3):402-7.

8. Friendly $L$, Roos $L$. The challenges nurses face regarding professional and personal responsibilities; 2008.

9. Dale B, Leland A, Dale JG. What factors facilitate good learning experiences in clinical studies in nursing: bachelor students' perceptions. ISRN Nurs. $2013 ; 2013$

10. Mwale OG, Kalawa R. Factors affecting acquisition of psychomotor clinical skills by student nurses and midwives in CHAM nursing colleges in Malawi: a qualitative exploratory study. BMC Nurs. 2016;15(1):30.

11. Upton P, Scurlock-Evans L, Williamson K, Rouse J, Upton D. The evidencebased practice profiles of academic and clinical staff involved in preregistration nursing students' education: a cross sectional survey of US and UK staff. Nurse Educ Today. 2015;35(1):80-5.

12. Walker S, Dwyer T, Moxham L, Broadbent M, Sander T. Facilitator versus preceptor: which offers the best support to undergraduate nursing students? Nurse Educ Today. 2013;33(5):530-5.

13. Chan DS, Ip WY. Perception of hospital learning environment: a survey of Hong Kong nursing students. Nurse Educ Today. 2007;27(7):677-84.

14. Papastavrou E, Dimitriadou M, Tsangari H, Andreou C. Nursing students' satisfaction of the clinical learning environment: a research study. BMC Nurs. 2016;15(1):44.

15. Sharif F, Masoumi S. A qualitative study of nursing student experiences of clinical practice. BMC Nurs. 2005;4(1):6.

16. Arkan B, Ordin Y, Yılmaz D. Undergraduate nursing students' experience related to their clinical learning environment and factors affecting to their clinical learning process. Nurse Educ Pract. 2018;29:127-32.

17. Jamshidi $\mathrm{L}$. The challenges of clinical teaching in nursing skills and lifelong learning from the standpoint of nursing students and educators. Procedia Soc Behav Sci. 2012:46:3335-8.

18. Hanson SE, MacLeod ML, Schiller CJ. 'It's complicated': Staff nurse perceptions of their influence on nursing students' learning. A qualitative descriptive study. Nurse Educ Today. 2018;63:76-80.
19. Bell SA, Rominski S, Bam V, Donkor E, Lori J. Analysis of nursing education in $\mathrm{G}$ hana: priorities for scaling-up the nursing workforce. Nurs Health Sci. 2013;15(2):244-9.

20. Asirifi M, Ogilvie L, Barton S, Aniteye P, Stobart K, Bilash O, Eliason C, Achempim-Ansong G, Kwashie A, Aziato L. Reconceptualising Preceptorship in clinical nursing education in Ghana; 2019.

21. Ghana Statistical Service. 2010 Population and Housing Census Distric analytical report Tamale Metropolis. Accra; 2014

22. Saarikoski $\mathrm{M}$, Isoaho $\mathrm{H}$, Warne $\mathrm{T}$, Leino-Kilpi $\mathrm{H}$. The nurse teacher in clinical practice: developing the new sub-dimension to the clinical learning environment and supervision (CLES) scale. Int J Nurs Stud. 2008:45(8):1233-7.

23. Papastavrou E, Lambrinou E, Tsangari H, Saarikoski M, Leino-Kilpi H. Student nurses experience of learning in the clinical environment. Nurse Educ Pract. 2010;10(3):176-82.

24. Saarikoski M, Warne T, Kaila $P$, Leino-Kilpi $H$. The role of the nurse teacher in clinical practice: an empirical study of Finnish student nurse experiences. Nurse Educ Today. 2009;29(6):595-600.

25. Gurková E, Žiaková K, Cibríková S, Magurová D, Hudáková A, Mrosková S Factors influencing the effectiveness of clinical learning environment in nursing education. Cent Eur J Nurs Midwifery. 2016;7(3):470-5.

26. Cremonini V, Ferri $P$, Artioli G, Sarli L, Piccioni E, Rubbi I. Nursing students' experiences of and satisfaction with the clinical learning environment: the role of educational models in the simulation laboratory and in clinical practice. Acta Bio Medica Atenei Parmensis. 2015;86(3Supp):194-204.

27. Carlson E, Idvall E. Nursing students' experiences of the clinical learning environment in nursing homes: a questionnaire study using the CLES+ T evaluation scale. Nurse Educ Today. 2014;34(7):1130-4.

28. Dimitriadou M, Papastavrou E, Efstathiou G, Theodorou M. Baccalaureate nursing students' perceptions of learning and supervision in the clinical environment. Nurs Health Sci. 2015;17(2):236-42.

\section{Publisher's Note}

Springer Nature remains neutral with regard to jurisdictional claims in published maps and institutional affiliations.

Ready to submit your research? Choose BMC and benefit from:

- fast, convenient online submission

- thorough peer review by experienced researchers in your field

- rapid publication on acceptance

- support for research data, including large and complex data types

- gold Open Access which fosters wider collaboration and increased citations

- maximum visibility for your research: over $100 \mathrm{M}$ website views per year

At BMC, research is always in progress.

Learn more biomedcentral.com/submissions 